\title{
Graphical User Interface for MODFLOW, Version 4
}

By Richard B. Winston

U.S. GEOLOGICAL SURVEY

Open-File Report 00-315 


\section{U.S. DEPARTMENT OF THE INTERIOR \\ BRUCE BABBITT, Secretary}

U.S. GEOLOGICAL SURVEY

Charles G. Groat, Director

Although the computer program described in this report has been tested and used by the U.S. Geological Survey (USGS), no warranty, expressed or implied, is made by the USGS as to the accuracy of the functioning of the program and related material. The code may be updated and revised periodically.

Any use of trade, product, or firm names in this publication is for descriptive purposes only and does not imply endorsement by the U.S. Government.

For additional information write to:

Office of Ground Water

U.S. Geological Survey

411 National Center

Reston, VA 20192
Copies of this report can be purchased from:

U.S. Geological Survey

Branch of Information Services

Box 25286

Denver, Colorado 80225-0286 


\section{Contents}

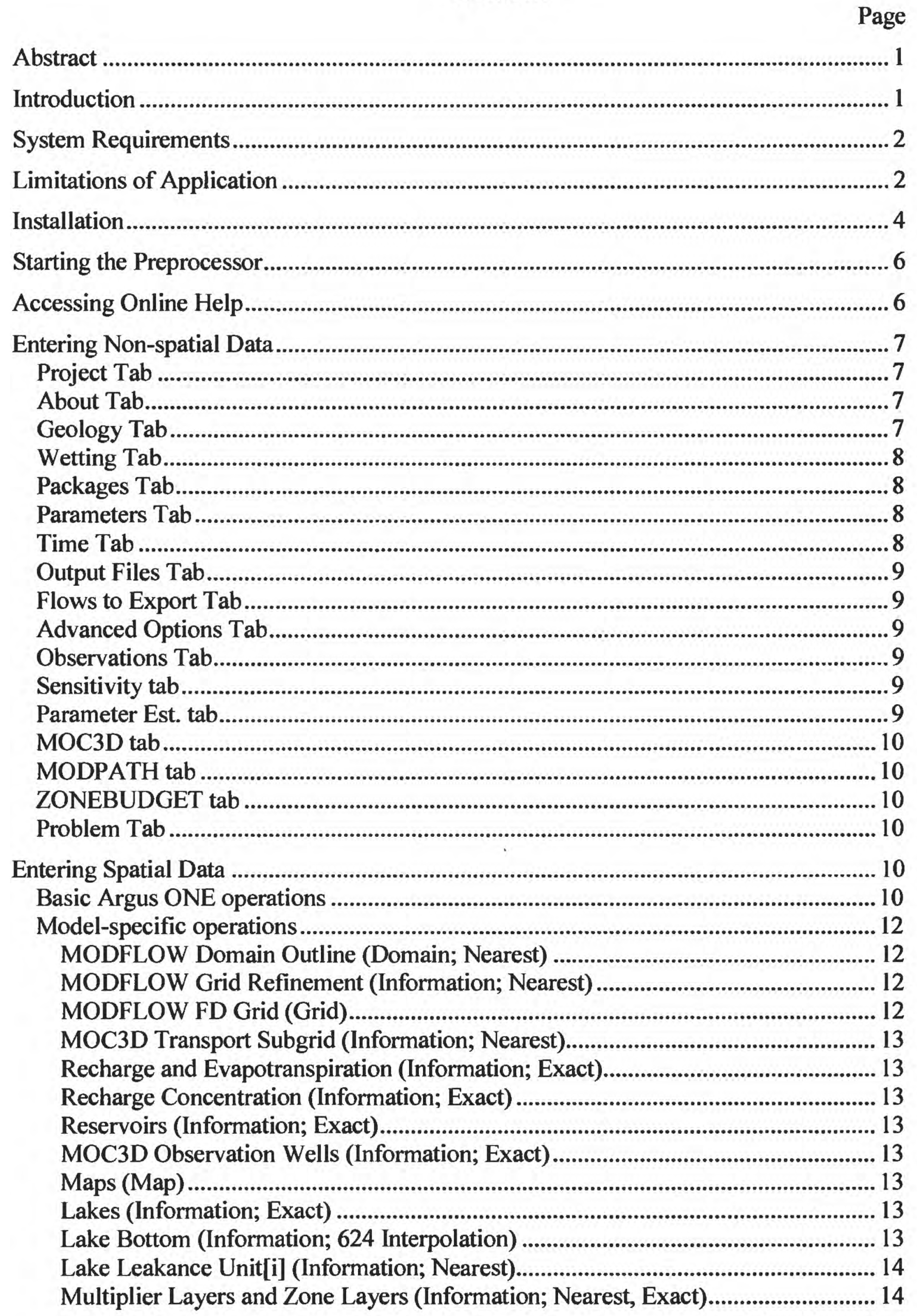


Head Observations[i] (Information; Nearest) ............................................................ 14

Weighted Head Observations[i] (Information; Nearest) ........................................... 14

GHB Observations[i], Drain Observations[i], and River Observations[i]

(Information; Exact) ............................................................................................ 14

Prescribed_Head Flux Observations[i] (Information; Exact) ....................................... 14

Advection Starting Points[i] (Information; Nearest).................................................... 14

Advection Observation Points[i] (Information; Nearest)........................................... 14

Elevation Top Unit[i] and Elevation Bottom Unit[i] (Information; 624

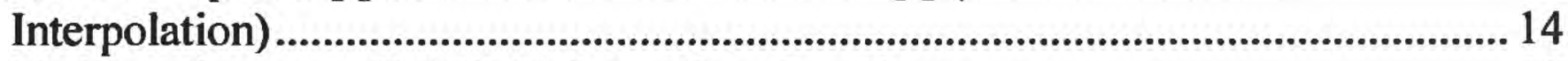

Added Inactive Area Unit[i] (Information; Exact)........................................................ 15

Prescribed Head Unit[i] (Information; Exact).......................................................... 15

Initial Head Unit[i] (Information; 624 Interpolation) .............................................. 15

Hydraulic Cond Unit[i] (Information; 624 Interpolation) .......................................... 15

Specific Yield Unit[i] and Specific Storage Unit[i] (Information; 624

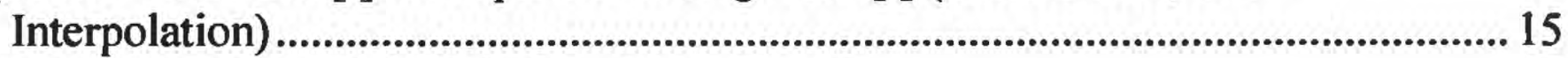

Wetting Threshold Unit[i] (Information; Exact) ...................................................... 15

Wells Unit[i], Line Wells Unit[i], and Area Wells Unit[i] (Information; Nearest,

Nearest, Exact) ...................................................................................................... 15

Point River Unit[i], Line River Unit[i], and Area River Unit[i] (Information;

Nearest, Nearest, Exact) ...................................................................................... 16

Point Drain Unit[i], Line Drain Unit[i], and Area Drain Unit[i] (Information; Nearest, Nearest, Exact) .................................................................................... 16

Point, Line, and Area Gen Head Bound Unit[i] (Information; Nearest, Nearest,

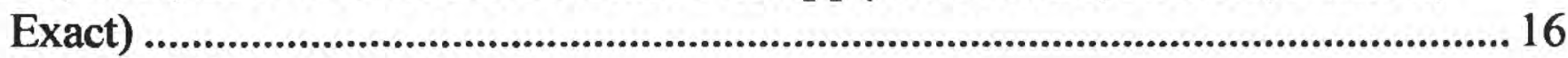

Stream Unit[i] (Information; Nearest)......................................................................... 16

Horizontal Flow Barrier Unit[i] (Information; Nearest) ............................................... 17

Point FHB Unit[i], Line FHB Unit[i], and Area FHB Unit[i] (Information;

Nearest, Nearest, Exact) ....................................................................................... 17

MODPATH Zone Unit[i] (Information; Exact) ......................................................... 17

MODPATH Particles Unit[i] (Information; Exact) ................................................... 17

Particle Regeneration Unit[i] (Information; Exact) .................................................... 17

Init Concentration Unit[i] (Information; Exact)......................................................... 17

Porosity Unit[i] (Information; Exact).......................................................................... 17

ZONEBDGT Unit[i] (Information; Exact) ............................................................... 17

Other Layers............................................................................................................. 18

Evaluating Expressions at Specific Locations ……………….............................................. 18

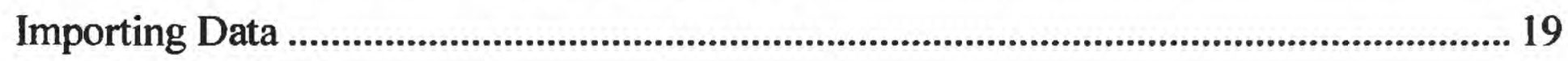

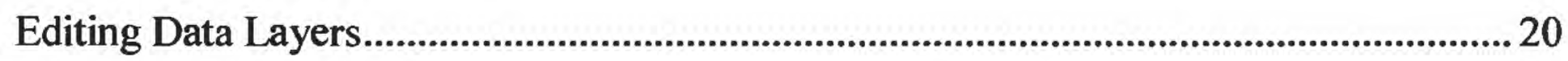

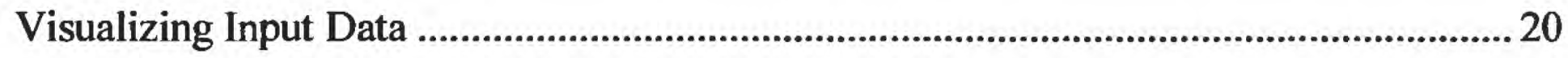

Running MODFLOW, MOC3D, MODPATH, or ZONEBUDGET ................................. 21

Visualizing Results....................................................................................................... 22

Visualizing Results from MODFLOW and MOC3D ……..............................................22

Contour Map ............................................................................................................ 24

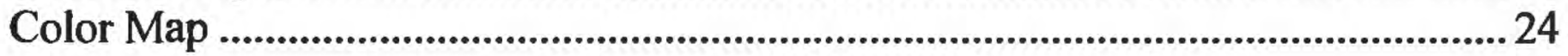


Three-Dimensional Surface Map ........................................................................ 24

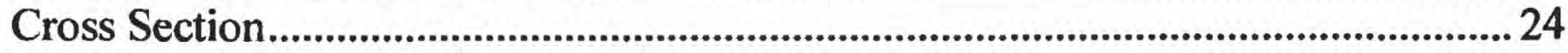

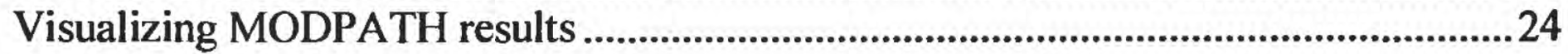

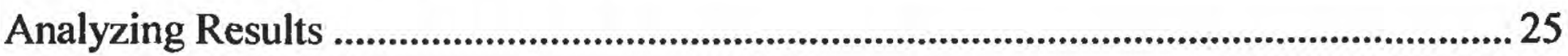

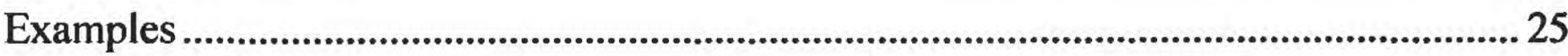

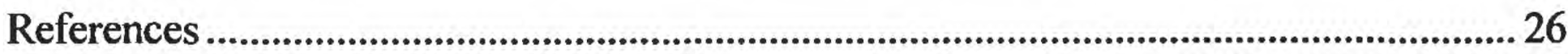

Tables

Table 1. Supported Packages in the MODFLOW GUI......................................................... 3

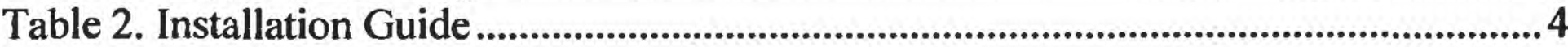

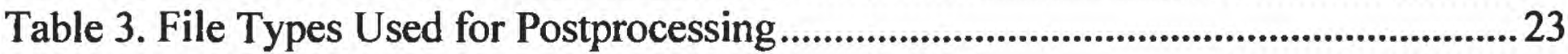




\title{
MODFLOW Graphical User Interface: Version 4
}

\author{
Richard B. Winston
}

\section{Abstract}

This report documents a new version of the MODFLOW Graphical User Interface for Argus ONE (MODFLOW GUI) that adds support for the U.S. Geological Survey's MODFLOW-2000 and the Reservoir, Transient Leakage, Interbed Storage, Lake, and Gage packages. The new version can also import existing MODFLOW-88 and MODFLOW-96 models. A utility program, GW_Chart, was developed in conjunction with the MODFLOW GUI and is used for post-processing of the output of MODFLOW. Also, in conjunction with the development of the MODFLOW GUI, three utility Plug-In Extensions (PIE's) were developed. One PIE facilitates importing gridded data into Argus ONE. This is helpful when attempting to reproduce an existing model in Argus ONE. Another PIE allows editing of data points on data layers. A third utility PIE allows expressions to be evaluated at specific X,Y coordinates. A series of example models were created and can be used to learn about the features of MODFLOW, Argus ONE, and the MODFLOW GUl.

\section{Introduction}

This report describes version 4 of the MODFLOW GUI. This report supercedes rather than supplements the three previous reports on the MODFLOW GUI (Shapiro and others, 1997; Hornberger and Konikow, 1998; and Winston 1999), but because the overall structure of the MODFLOW GUI is similar to that in previous versions, information and concepts in those reports may still be useful. The primary documentation for version 4 of the MODFLOW GUI, however, is not this document but the help system for the program. The help system describes all the options available in the program and how to use them.

Version 4 of the MODFLOW GUI represents a significant advance over version 3. Most importantly, it now supports MODFLOW-2000 (Harbaugh and others, 2000; Hill and others, 2000) as well as MODFLOW-96 (Harbaugh and McDonald, 1996a, 1996b). In addition, version 4 also supports the Interbed Storage (Leake and Prudic, 1991), Transient Leakage (Leake and others, 1994), Reservoir (Fenske and others, 1996), Lake (Merritt and Konikow, in press) and Gage (Merritt and Konikow, in press) packages.

In conjunction with preparation of version 4 of the MODFLOW GUI, a utility program, GW_Chart, was developed. GW_Chart incorporates the functionality of two previous programs: Budgeteer and Hydrograph Extractor (Winston, 1999). It also creates most of the graphs recommended by Hill (1998) for aid in calibrating models. In addition it extracts information from the output files for MODFLOW, MOC3D, or the Gage package, and prepares graphs of the data. It can also prepare Piper diagrams. The programs allow the user to save data to either graphics or text files. If saved to a graphic file, the data may be imported directly into other programs such as word processors. If 
saved as a text file, the data may be easily imported into spreadsheet programs for further analysis.

Three utility Plug-In Extension (PIE) for Argus ONE was prepared in conjunction with version 4 of the MODFLOW GUI. The GriddedImport PIE is designed to facilitate importing data from existing models into Argus ONE. After the user reproduces the grid of their original model in Argus ONE, GriddedImport can be used to create data layers containing the array data from the original model. It is described in greater detail in the section of this report entitled "Importing Data". Another utility PIE allows users to edit the data in data layers. It is described in the section of this report entitled "Editing Data Layers". A third utility PIE allows expressions to be evaluated at specific X,Y locations. It is described in the section of this report entitled "Evaluating Expressions at Specific Locations". Two other utility PIEs were documented previously in Winston (1999): EditContours and RotateCells. These two utility PIEs remain virtually unchanged.

This report describes the most recent major changes and additions to the GUI. A series of examples is available at http://water.usgs.gov/nrp/gwsoftware/modflow-gui/modflow-gui.html that illustrate how to use the MODFLOW GUI. The examples should be especially helpful to users who are either unfamiliar with MODFLOW and related programs or who are unfamiliar with Argus ONE.

\section{System Requirements}

The revised MODFLOW-GUI has been tested on personal computers with Windows 95 and Windows NT 4.0. It has not been tested extensively on Windows 98 or Windows 2000. The user must have the Windows version of Argus Open Numerical Environments (Argus $\mathrm{ONE}^{\mathrm{TM}}$ ). Argus $\mathrm{ONE}^{\mathrm{TM}}$ largely determines hardware requirements. At the time this was written, the requirements for Argus $\mathrm{ONE}^{\mathrm{TM}}$ were the following:

\begin{tabular}{ll}
\hline Hardware & \multicolumn{1}{c}{ Requirement } \\
\hline CPU & $\begin{array}{l}\text { Pentium, Pentium Pro or more recent } \\
\text { processor recommended } \\
\text { Required }\end{array}$ \\
Mouse & $32 \mathrm{MB}$ or more recommended \\
RAM & $7 \mathrm{MB}$ \\
DISK & VGA/SVGA Display, 65,000 colors \\
Display &
\end{tabular}

In addition, the MODFLOW-GUI requires a display with a resolution of at least $755 \times 613$ (width $\times$ height).

\section{Limitations of Application}

At the time this document was written some of the supported packages function only with MODFLOW-96 and so are not supported in the MODFLOW-2000 portion of the MODFLOW GUI. These packages include the Interbed Storage Package, the Transient Leakage Package, and the Stream package. If new versions of these packages are written that do work with MODFLOW-2000 and the MODFLOW GUI is modified to 
support the new versions, this will be noted in the online help. Table 1 lists the programs and packages currently supported in the MODFLOW GUI.

Table 1. Supported Packages in the MODFLOW GUI

\begin{tabular}{|c|c|c|c|}
\hline Program & Process or Package & MODFLOW-96 & MODFLOW-2000 \\
\hline MODFLOW & Basic package (BAS) & Supported & Supported \\
\hline MODFLOW & $\begin{array}{l}\text { Block-Centered Flow } \\
\text { package (BCF) }\end{array}$ & Supported & Supported \\
\hline MODFLOW & $\begin{array}{l}\text { Time-Variant Specified- } \\
\text { Head package (CHD) }\end{array}$ & Not supported & Not supported \\
\hline MODFLOW & $\begin{array}{l}\text { Direct Solution solver } \\
\text { (DE4) }\end{array}$ & Supported & Supported \\
\hline MODFLOW & Drain package (DRN) & Supported & Supported \\
\hline MODFLOW & $\begin{array}{l}\text { Evapotranspiration } \\
\text { package (EVT) }\end{array}$ & Supported & Supported \\
\hline MODFLOW & $\begin{array}{l}\text { Flow and Head } \\
\text { Boundary package } \\
\text { (FHB) }\end{array}$ & Supported & Supported \\
\hline MODFLOW & $\begin{array}{l}\text { Generalized Finite- } \\
\text { Difference package } \\
\text { (GFD) }\end{array}$ & Not supported & Not supported \\
\hline MODFLOW & $\begin{array}{l}\text { General-Head Boundary } \\
\text { package (GHB) }\end{array}$ & Supported & Supported \\
\hline MODFLOW & $\begin{array}{l}\text { Horizontal-Flow-Barrier } \\
\text { package (HFB) }\end{array}$ & Supported & Supported \\
\hline MODFLOW & $\begin{array}{l}\text { Interbed Storage package } \\
\text { (IBS) }\end{array}$ & Supported & Not supported \\
\hline MODFLOW & Lake package (LAK) & Supported & Supported \\
\hline MODFLOW & $\begin{array}{l}\text { Preconditioned } \\
\text { Conjugate Gradient } \\
\text { (Version 2) solver } \\
\text { (PCG) }\end{array}$ & Supported & Supported \\
\hline MODFLOW & Recharge package $(\mathrm{RCH})$ & Supported & Supported \\
\hline MODFLOW & Reservoir package (RES) & Supported & Supported \\
\hline MODFLOW & River package (RIV) & Supported & Supported \\
\hline MODFLOW & $\begin{array}{l}\text { Strongly lmplicit } \\
\text { Procedure solver (SIP) }\end{array}$ & Supported & Supported \\
\hline MODFLOW & $\begin{array}{l}\text { Slice-Successive } \\
\text { Overrelaxation solver } \\
\text { (SOR) }\end{array}$ & Supported & Supported \\
\hline MODFLOW & Stream package (STR) & Supported & Not supported \\
\hline MODFLOW & $\begin{array}{l}\text { Transient-Leakage } \\
\text { package (TLK) }\end{array}$ & Supported & Not supported \\
\hline MODFLOW & Well package (WEL) & Supported & Supported \\
\hline
\end{tabular}


Table 1. (Continued)

\begin{tabular}{|c|c|c|c|}
\hline Program & Process or Package & MODFLOW-96 & MODFLOW-2000 \\
\hline MODFLOW & $\begin{array}{l}\text { Layer Property Flow } \\
\text { package (LPF) }\end{array}$ & Not supported & Supported \\
\hline MODFLOW & $\begin{array}{l}\text { Hydrograph package } \\
\text { (HYDMOD) }\end{array}$ & Not supported & Not supported \\
\hline MODFLOW & Observation process & Not supported & Supported \\
\hline MODFLOW & $\begin{array}{l}\text { Sensitivity Analysis } \\
\text { process }\end{array}$ & Not supported & Supported \\
\hline MODFLOW & $\begin{array}{l}\text { Parameter Estimation } \\
\text { process }\end{array}$ & Not supported & Supported \\
\hline MOC3D & MOCIMP solver & Supported & Not Supported \\
\hline MOC3D & ELLAM solver & Supported & Not Supported \\
\hline MOC3D & Age package & Supported & Not Supported \\
\hline MOC3D & Double Porosity package & Supported & Not Supported \\
\hline MOC3D & $\begin{array}{l}\text { Simple Reactions } \\
\text { package }\end{array}$ & Supported & Not Supported \\
\hline MODPATH & & Supported & Supported \\
\hline ZONEBUDGET & & Supported & Supported \\
\hline RESAN-2000 & & Not Supported & Supported \\
\hline YCINT-2000 & & Not Supported & Supported \\
\hline BEALE-2000 & & Not Supported & Supported \\
\hline
\end{tabular}

\section{Installation}

An installer program is available for installation of the MODFLOW GUI. If the installer program is not used, table 2 can be used as a guide for manual installation.

Except for ctl3d32.dll, 1f90wiod.dll, and Lf90.eer, all the files used by the PIE should be placed in the ArgusPIE directory or in subdirectories under the ArgusPIE directory. ReaArr.dll, modflw96.dll, MODFLOW.cnt, MODFLOW.hlp, and the *.met files should be placed in the same directory as MFGUI 40.dll. Unless otherwise noted, it is generally a good idea to place each PIE in its own subdirectories under the ArgusPIE directory. The export templates used by the PIE (*.met), and the help system files (modflow.hlp and modflow.cnt) should be placed in the same directory as the MODFLOW PIE (MFGUI_40.dll). Ctl3d32.dll is only required for Windows NT 3.51. If required, it should be placed in the System 32 directory under the main directory for the operating system (normally WinNT). Many, but not all, users will already have $\mathrm{Ctl} 3 \mathrm{~d} 32 . \mathrm{dll}$ on their computer and in such cases they generally should not replace the existing version with the one distributed with the PIE. Export templates that are meant to be modified and executed manually by the user may be placed in any convenient location. These include contour2data.met and statistics.met. All the files comprising the PIE are available from the U.S. Geological Survey at http://water.usgs.gov/nrp/gwsoftware/modflow-gui/modflow-gui.html, but they require an executable version of Argus $\mathrm{ONE}^{\mathrm{TM}}$ (version $4.2 .0 \mathrm{q}$ or higher) to operate. Although not required to operate the MODFLOW PIE, the EditContours, 
EditDataLayer, EvalAtXY, RotateCells, MODFLOW_ReadFileValue, GetMyDirectory, and GriddedImport PIE's and the SelectChar, WaitForMe, and GW Chart programs and MODFLOW tutorial were designed for use with models in the MODFLOW PIE and are thus distributed with the MODFLOW PIE. They may also be useful for other purposes.

Table 2. Installation Guide

\begin{tabular}{|c|c|}
\hline Files required for installation & Location to install \\
\hline MFGUI_40.dll & $<$ Argus directory $>$ |ArgusPIEIMODFLOW \\
\hline ReaArr.d̄ll & $<$ Argus directory $>\backslash$ ArgusPIELMODFLOW \\
\hline modflw96.dll & $<$ Argus directory $>\backslash$ ArgusPIEIMODFLOW \\
\hline MODFLOW.cnt & $<$ Argus directory $>$ |ArgusPIEIMODFLOW \\
\hline MODFLOW.hlp & $<$ Argus directory $>$ AArgusPIEIMODFLOW \\
\hline $\begin{array}{l}\text { *.met (see readme.txt file for } \\
\text { details) }\end{array}$ & $<$ Argus directory $>\backslash$ ArgusPIEIMODFLOW \\
\hline MODFLOW_JoinFiles.dll & $<$ Argus directory $>\backslash$ ArgusPIEUoinFiles \\
\hline MODFLOW_BlockList.dll & $<$ Argus directory $>$ AArgusPIElBlockList \\
\hline MODFLOW_ReadFileValue.dll & $<$ Argus directory $>\backslash$ ArgusPIE $\backslash$ ReadFileValue \\
\hline MODFLOW_List.dll & $<$ Argus directory $>\backslash$ ArgusPIELList \\
\hline EditDataLayer.dll & $<$ Argus directory $>\backslash$ ArgusPIELEditDataLayer \\
\hline GriddedImport.dll & $<$ Argus directory $>\backslash$ ArgusPIEIGriddedImport \\
\hline GriddedImport.hlp & $<$ Argus directory $>\backslash$ ArgusPIElGriddedImport \\
\hline GriddedImport.cnt & $<$ Argus directory $>$ |ArgusPIElGriddedImport \\
\hline EvalAtXY.dll & $<$ Argus directory $>$ |ArgusPIElEvalAtXY \\
\hline GetMyDirectory.dll & $<$ Argus directory $>\backslash$ ArgusPIElGetMyDirectory \\
\hline SelectChar.exe & $<$ Argus directory $>$ AArgusPIElGetMyDirectory \\
\hline WaitForMe.exe & $<$ Argus directory $>\backslash$ ArgusPIE $\mid$ GetMyDirectory \\
\hline MODFLOW_ProgressBarPIE.dll & $<$ Argus directory $>\backslash$ ArgusPIE $\backslash$ ProgressBarPIE \\
\hline lf90wiod.dll & $<$ Windows directory $>$ SSystem 32 \\
\hline Lf90.eer & $<$ Windows directory $>$ |System 32 \\
\hline Ct13d32.dll (Windows NT 3.51) & $<$ Windows directory $>\mid$ System 32 \\
\hline
\end{tabular}

Previous versions of the GUI (Shapiro and others, 1997; Hornberger and Konikow, 1998) used a number of array PIE's that are not used by the current version of the PIE (Chk_BlockArray.dll, Chk_LayArray.dll). If those files are present, they may be deleted without affecting the new version of the MODFLOW-GUI. Previous versions of the MODFLOW-GUI and post-processing PIE's (mfgui_30.dll, mfgui_20.dll, mfpost20.dll, mcpost10.dll) should be deleted from the Argus PIE directory because they will interfere with the new version of the PIE. The functions performed by all of these older PIE's have been incorporated into the new GUI. If version 3 of the MODFLOWGUI was installed using its installer, it should be uninstalled with its uninstaller.

Executable versions of MOC3D (Version 1.2 or later), MODFLOW-96, MODFLOW-2000, MODPATH, and ZONEBDGT must be installed to run these models from the Argus ONE ${ }^{\mathrm{TM}}$ environment. The MODFLOW-96 code and the MOC3D code are integrated into one code (MOC3D). MODFLOW-96 or MODFLOW-2000 (without MOC3D) are executed when using the GUI to simulate ground-water flow only, without 
transport; MOC3D is executed when simulating ground-water flow with transport. Although it does not matter which compiler was used to create the executable versions of the models, it is important that they all be compiled with compatible compilers. This is because ZONEBDGT and MODPATH read binary files created by MOC3D and MODFLOW-96. The format of the binary files is compiler-dependent. The MODFLOW GUI only can read files created with the Lahey LF90 compiler or a compatible compiler. If another compiler is used for MODFLOW, ReaArr.dll should be recompiled with the other compiler if the user desires to read binary files with the MODFLOW GUI. The versions of these programs on the USGS software web site are all compatible.

The MODFLOW-GUI consists of a dynamic-link library (MFGUI_40.dll) that provides the core functionality. It provides the Project Info, Run MODFLOW, and a variety of other dialog boxes. It is responsible for creating and destroying MODFLOWrelated layers and parameters in the Argus $\mathrm{ONE}^{\mathrm{TM}}$ project, and for accessing its contextsensitive help. It processes the model-related export templates and prepares them for execution by Argus $\mathrm{ONE}^{\mathrm{TM}}$. It also provides a number of hidden PIE functions that are called when the export templates are executed. The model-related export templates are the files MODFLOW.met, MF_Modflow2000.met, ZoneBud.met, and MODPATH.met. These files contain the instructions for creating the input files for MODFLOW-96, MODFLOW-2000, MOC3D, ZONEBDGT, and MODPATH. When they are executed, the export templates use PIE functions provided by the following dll's: List.dll, BlockList.dll, ProgressBar.dll, and JoinFiles.dll. Of these, only ProgressBar.dll will be visible to the user. It displays a progress bar during the execution of export templates and provides an estimate of the time required until execution of the export template is complete. It also displays error and warning messages. Modflow.hlp and Modflow.cnt provide the online help for the PIE. Finally, ctl3d32.dll, a dynamic-link library from Microsoft Corporation ${ }^{\mathrm{TM}}$, provides the three-dimensional appearance of certain portions of the dialog boxes when the PIE is operated on computers using the Windows NT 3.51 operating system.

\section{Starting the Preprocessor}

The user can start a new model or open an existing model in the same way as in previous versions of the MODFLOW-GUI. To start a new model, start Argus ONE ${ }^{\mathrm{TM}}$ and select PIEs|New MODFLOW Project. To open an existing model, start Argus $\mathrm{ONE}^{\mathrm{TM}}$, select File|Open...., and then select the file to open. In some cases, if the user opens a model created by the previous version of the MODFLOW/MOC3D PIE, the PIE will need to update the data for the model. If this is the case, a message will notify the user that he will need to open the Project Info dialog box and close it again. The data will be automatically updated when the user clicks OK after opening the Project Info dialog box. Other layers, such as group layers for each geological unit, may also be created at the same time. (The group layers provide a convenient mechanism for organizing Argus $\mathrm{ONE}^{\mathrm{TM}}$ layers but are not required for the model to operate.)

\section{Accessing Online Help}

The online help is the primary documentation of the MODFLOW GUI. The online help for the MODFLOW GUI can be accessed in several ways. 
1. Locate the file MODFLOW.hlp in the directory in which the MODFLOW GUI is installed and double click on it inside Windows Explorer.

2. Start Argus ONE and select the PIEs|Modflow Help menu item.

3. In most dialog boxes provided by the MODFLOW GUI, there is a button labeled Help. Click on such buttons to access the online help.

4. In many dialog boxes provided by the MODFLOW GUI, there will be a ? icon in the upper right hand corner. The online help can be accessed by clicking on such icons and then clicking on one of the controls on the dialog box such as an edit box or combo box.

In addition to the online help system, there are several other resources that users may find useful.

1. A "Tip of the day" dialog box will appear when starting a new MODFLOW project or opening an existing MODFLOW project. This feature can be deactivated, if desired, by unchecking the check box labeled "Show tips at startup" in the lower left corner of the tip dialog box. It can be reactivated on the Advanced Options tab of the Project Info dialog box.

2. If the mouse cursor is held over a control on some dialog boxes, a tool-tip may appear that gives a brief explanation of the purpose of the control.

3. Two tutorials are available as described in the section of this report entitled "Examples".

\section{Entering Non-spatial Data}

Non-spatial data are entered in the Project Info dialog box. The user can display it by selecting PIEs|Edit Project Info... Most of the non-spatial data are the same as in previous versions of the MODFLOW-GUI (Shapiro and others, 1997; Hornberger and Konikow, 1998; Winston, 1999). However, MODFLOW-2000 requires additional information relating to parameters that was not present in previous versions of the MODFLOW GUI. Complete explanations of all items in the Project Info dialog box are included in the online help. This section presents a short summary of the major tasks performed with the Project Info dialog box.

\section{Project Tab}

The Project tab is the first tab that seen when opening the Project Info dialog box. It is used to set the project title, the length and time units of the model and the programs and processes that will be used in the model.

\section{About Tab}

The About tab gives the version of the MODFLOW GUI that is running, email addresses and phone numbers for technical support, and bibliographic citations of the MODFLOW GUI.

\section{Geology Tab}

The Geology tab is used to define the geologic units that will be used in the model and some of the information about the units. A geologic unit, in this context, need not be the same as a model layer. Each geologic unit may comprise one or more model layers. The number of model layers in a geologic unit is set by the vertical discretization of the 
geologic unit, which is defined in the column of the table labeled V. Discretization. The full width of the table is too wide to fit in the dialog box so users may have to scroll to the right to see some of the entries in the table. The widths of individual columns may be changed by putting the mouse over the line separating the columns in the column header, holding down the mouse button, and dragging with the mouse until the column is at the desired width.

\section{Wetting Tab}

The Wetting tab is used to activate and set options for rewetting of dry cells. Users should be aware that using the wetting option could cause model instability. More information is available in the documentation for the Block-Centered Flow and Layer Property Flow packages (McDonald and others, 1992; Harbaugh and others, 2000) and in the online help for the MODFLOW GUI.

\section{Packages Tab}

The Packages tab is used to choose the packages that will be used in the model. Most packages are activated by selecting a check box for that package on one of the subtabs of the Packages tab. In cases, where two or more packages can not both be used in the same model, radio buttons are used instead of check boxes. For example, only one solver may be used in a model although four solver packages are available so the user must use radio buttons to select a solver. If the user wishes to temporarily remove a package from the model but without removing the geospatial information for that package from the Argus ONE project, the user can uncheck the Use checkbox next to the checkbox for the package. When the check box for a package is checked, other controls relating to that package may also be enabled.

The Gage package is an exception to the above. It is activated by setting the Gage Argus ONE parameter for a Lake to true. A revised version of the Stream Package may also work with the Gage package in the future. If so, the MODFLOW GUI may be revised to activate the Gage package with a Gage Argus ONE parameter for individual streams.

Only one flow package may be used with a model. For MODFLOW-96, only one flow package is supported: the Block-Centered Flow package. For MODFLOW-2000, both the Block-Centered Flow and Layer Property Flow packages are supported. If a MODFLOW-2000 model is changed to a MODFLOW-96 model, the selected flow package will be changed to the Block-Centered Flow package and a warning will be given to the user.

\section{Parameters Tab}

The Parameters tab is where MODFLOW-2000 parameters are defined as well as non-spatial information for the related zone and multiplier arrays. The spatial information is defined in Argus ONE information layers.

\section{Time Tab}

The Time tab is used to define the stress periods in the model. 


\section{Output Files Tab}

The Output Files tab is used to define the root name for the model input files and the timing and nature of output from the model.

\section{Flows to Export Tab}

The Flows to Export tab is used to specify which packages will write their flow terms to the cell-by-cell flow file. This tab is only visible if the checkbox labeled Specify which flows to save on the Output Files tab is checked.

\section{Advanced Options Tab}

The Advanced Options tab is used to specify a number of infrequently used options. More information is available in the online help for the MODFLOW GUI.

\section{Observations Tab}

The Observations tab is used to specify non-spatial information related to observations that are to be compared with model results. The spatial information is defined in Argus ONE information layers. There are separate sub tabs for each type of observation.

The table of variances and covariances in the MODFLOW GUI that appears with some types of observations is a little different from that actually exported to MODFLOW so the differences need to be discussed. Each observation is defined by a contour on an Argus ONE information layer. Each such contour has a Statistic[i] Argus ONE parameter. Normally, the Statistic[i] parameter is either a scaled variance, a scaled standard deviation, or a scaled coefficient of variation depending on the value of the STAT-FLAG Argus ONE parameter. In some cases, however, two or more observations may not be completely independent of one another. If this is the case, their covariances are not equal to 0 . In the MODFLOW GUI, the user only needs to enter values in the table for observations that have a non-zero covariance with at least one other observation. If an observation is not entered in the table, its variance will be specified by the Statistic[i] parameter of the contour that defines the observation and the covariances with all other observations will be 0 . When the variance-covariance table is used, STATFLAG is ignored.

More information is available in the online help for the MODFLOW GUI and in the documentation for the observation process (Hill and others, 2000).

\section{Sensitivity tab}

The Sensitivity tab is where the information for the sensitivity process is defined. The user must choose how many parameters will be used for sensitivity analysis and whether they will be used for parameter estimation. The user also controls printing of sensitivity data here.

\section{Parameter Est. tab}

The Parameter Est. tab has a series of subtabs that are used to define the information for the parameter estimation process. For example, the maximum number of parameter estimation iterations and prior information equations are specified here. 


\section{MOC3D tab}

The MOC3D tab has a series of subtabs that are used to define the non-spatial information for MOC3D. For example, the first and last geologic units used in the MOC3D subgrid are specified here.

\section{MODPATH tab}

The MODPATH tab has a series of subtabs that are used to define the non-spatial information for MODPATH. For example, the user can choose whether to create, endpoint, time-series, or pathline plots here.

\section{ZONEBUDGET tab}

The ZONEBUDGET tab is used to define the non-spatial information for ZONEBUDGET. For example, the user can define composite zones here.

\section{Problem Tab}

This tab is only shown when the PIE has failed to read some of the information in a model. The data that it was unable to read are shown on this tab. If the "Show PIE Developer" button is clicked, the developer of the PIE that created the model will be shown. The user should contact that person for assistance.

The data on this tab are not saved with the model, so if the model is saved, the information shown on this tab will be lost.

\section{Entering Spatial Data}

\section{Basic Argus ONE operations}

Argus ONE creates a series of two-dimensional layers that can be used for specifying information about a model. These Argus ONE layers are not the same as model layers. Instead, Argus ONE layers are used to specify and store information about the model. Each geologic unit in the model will have a series of Argus ONE layers related to it. In addition, there will be Argus ONE layers that are not related to a specific geologic unit. The Argus ONE layers are of various types. Grid layers, for example can be used to store a grid. Data layers store a series of data points used for fast interpolation. Information layers store contours (points, lines or polygons). Map layers can be used for contour maps, scanned images, and other things. Domain layers store information used to generate a grid (or a mesh for finite-element models).

The MODFLOW GUI creates a series of Argus ONE layers that are required for Argus ONE to create a MODFLOW model. For example, it creates a grid layer named MODFLOW FD Grid and an information layer named Elevation Top Unit 1 that specifies the top of the uppermost geologic unit. The layers created by the GUI are locked so that they can not be removed accidentally. However, Argus ONE lets the user unlock and delete layers. If an Argus ONE layer required by the MODFLOW GUI is accidentally deleted, the MODFLOW GUI will recreate it the next time the user selects PIEs|Edit Project Info... and then clicks on the OK button.

Most types of Argus ONE layers can have parameters. The parameters of Argus ONE layers are completely different from the parameters of MODFLOW-2000. To 
avoid confusion, parameters in the document will be referred to as either Argus ONE parameters or as MODFLOW-2000 parameters. (MODFLOW-2000 parameters are numeric values that determine properties such as hydraulic conductivity or river-cell conductance. MODFLOW-2000 parameters may be estimated using the ParameterEstimation process.)

Argus ONE parameters are used to store data of a specific type on an Argus ONE layer. For example, on the Hydraulic Cond Unitl Argus ONE layer, there are two Argus ONE parameters: $\mathrm{Kx}$ and $\mathrm{Kz}$. $\mathrm{Kx}$ is the horizontal hydraulic conductivity in the grid's $\mathrm{X}$ direction (in the order of increasing column numbers). $\mathrm{Kz}$ is the vertical hydraulic conductivity. Thus $\mathrm{Kx}$ and $\mathrm{Kz}$ store two different types of information.

The user can draw contours on an Argus ONE Information layer if it is the active layer. As explained in the documentation for Argus ONE, there are several ways to make a layer the active layer but the easiest is to use a secondary window provided by Argus ONE (the Layers floater) that shows a list of the Argus ONE layers with several icons to the left of their names. One of the icons is either an open or closed eye (indicating whether or not the layer is visible). If the user clicks to the left of the eye icon for a layer, that layer will be activated and a check mark will appear left of the eye icon. (Only one layer can be the active layer at a time.)

Once the desired layer has been made active, contours can be drawn on it. There are three types of contours: point contours, open contours, and close contours. Point contours are individual points. Open contours consist of a series of line segments that do not join up to form a polygon. Close contours are polygons. To draw a contour, follow the instructions in the section of the Argus ONE documentation (Argus Interware, Inc., 1997) entitled Creating Contours in chapter 2 (p.96). When the contour is finished, a dialog box will appear with a list of the Argus ONE parameters for the layer and their values. New values for the contour can be entered in this dialog box. The default value for an Argus ONE parameter is determined by the expression for the parameter. If no value for a parameter is entered, than the value for the contour will be changed if the expression changes or if the data referred to by the expression changes. However, values that are entered for Argus ONE parameters on a contour override the expressions for those parameters. If a contour value overrides an expression and the user wishes to use the expression instead of the contour value, double-click on the contour and delete the values of the Argus-ONE parameters that should be set using expressions.

As can be seen from the paragraph above, expressions are an important part of Argus ONE. They are, in fact, one of its most powerful features. An expression can be used to link a parameter to another layer or another parameter on the same layer. Expressions can also incorporate functions of a variety of types. Expressions are described in the section entitled "Creating and Editing Expressions" in Chapter 3 of the Argus ONE documentation (p. 159). To make the best use of Argus ONE, the user must understand expressions and how they work.

At each location in an Argus ONE Information layer, the value of the parameters is defined by the contours and/or expressions of the layers. However, the manner in which contours affect the value at any location is affected by the contour interpretation method. The three basic options are "Nearest", "Exact", and "Interpolation". The section of the Argus ONE documentation (Argus Interware, Inc., 1997) entitled "Contours 
Interpretation Methods" in Chapter 2 of the Argus ONE documentation explains these options (p. 116).

New users of Argus ONE are particularly advised to read the sections of the Argus ONE documentation (Argus Interware, Inc., 1997) dealing with adding and manipulating layers (Part 2, Chapter 1: The Argus ONE Workplace: Layers, p. 67), Data layers (Supplements version 2.5: Working with Data Layers, p. 4 s2.5), and the "Rotate and Scale", "Drawing Size" and "Scale and Units" menu items under the "Special" menu item (p. 61-66, and 14 s3 - 16 s3).

\section{Model-specific operations}

The MODFLOW GUI creates a layer structure specialized for the creation of MODFLOW and related models (MOC3D, MODPATH, and ZONEBUDGET). The online help for the MODFLOW GUI contains a detailed description of each layer and its Argus ONE parameters. This section briefly describes the most commonly used layers. Consult the online help for detailed information.

In many cases, each geologic unit will have a layer that has the same name as a layer in another unit except for the number that terminates the name of the layer. In such cases, this report will use [i] where " $i$ " is the unit number to specify all the occurrences of the layer. For example geologic unit 1 has a layer named Elevation Top Unit1 and the next geologic unit has one named Elevation Top Unit2. All such layers will be referred to as Elevation Top Unit[i]. There may also be several related layers that are identical in name except for their final number even though they are not related to a specific geologic unit. An example is Head Observations1, Head Observations2, etc. The "i" designation is used for those as well.

In the list of layers that follows, the Layer name is followed by the layer type such as "Information" or "Data" and the interpretation method (if applicable). The descriptions of the layers are in the same order in which they would be found in the model.

\section{MODFLOW Domain Outline (Domain; Nearest)}

Use MODFLOW Domain Outline to specify the boundary of the model. Draw a closed contour on this layer surrounding the area of the model. The layer has one parameter named MODFLOW Grid Cell Size. Assign that parameter the desired grid cell size. If the model is to have a non-uniform grid spacing, open contours may be used on this layer or any type of contour on MODFLOW Grid Refinement layer to specify non-uniform grid spacing. Any closed contours on the MODFLOW Domain Outline layer inside the outer closed contour will designate inactive areas.

\section{MODFLOW Grid Refinement (Information; Nearest)}

MODFLOW Grid Refinement is used to specify locations where the grid cell size should be smaller than that specified on the MODFLOW Domain Outline layer. Either open or closed contours may be used.

\section{MODFLOW FD Grid (Grid)}

MODFLOW FD Grid represents the MODFLOW finite-difference grid. A grid can only be created on this layer. Once the MODFLOW Domain Outline has been 
defined, make the MODFLOW FD Grid layer the active layer and then click with the "Magic Wand" ${ }^{-}$inside the domain outline to create the grid. The grid layer has many parameters that can be used for visualizing the input data. See the section entitled

"Visualizing Input Data" later in this report.

\section{MOC3D Transport Subgrid (Information; Nearest)}

MOC3D Transport Subgrid is used to specify the extent of the MOC3D

subgrid. If contours are present on this layer, the maximum and minimum $\mathrm{X}$ and $\mathrm{Y}$ coordinates of the contours determine the extent of the subgrid used for MOC3D.

\section{Recharge and Evapotranspiration (Information; Exact)}

The Recharge and Evapotranspiration layers are used specify the rates of recharge and evapotranspiration and the layer or layers to which recharge or evapotranspiration are applied. The vertical distribution of recharge and evapotranspiration are also affected by the recharge option and evapotranspiration option specified in Project Info dialog box.

\section{Recharge Concentration (Information; Exact)}

Recharge Concentration is used to specify the concentration of solute in recharge for MOC3D.

\section{Reservoirs (Information; Exact)}

The Reservoirs Argus ONE layer is used to define the locations of reservoirs for the Reservoir package.

\section{MOC3D Observation Wells (Information; Exact)}

MOC3D Observation Wells is used to specify the location of observation points for MOC3D.

\section{Maps (Map)}

The Maps layer is useful for storing scanned images or maps imported from DXF or Shape files. The Maps layer may be used for whatever purpose the user desires; the data in it will not affect any of the simulations. To use information on the map layer to set up your model, it must first be copied to an information layer or traced in an information layer.

\section{Lakes (Information; Exact)}

The Lakes Argus ONE layer is used to define the locations of lakes for the Lake package.

\section{Lake Bottom (Information; 624 Interpolation)}

Lake Bottom is used to specify a spatially varying lake bottom in a lake. There is an Argus ONE parameter on the Lakes layer, which is linked to the Lake Bottom layer. If that parameter is overridden by a contour, the value specified for the contour will be used rather than data from the Lake Bottom layer. 


\section{Lake Leakance Unit[i] (Information; Nearest)}

Lake Leakance Unit[i] layers are used to define the Lake Leakance for the lake package. Leakance is simply the thickness of the lakebed times the hydraulic conductivity. Two Argus ONE parameters are used rather than a single one to facilitate having different spatial distributions of the lakebed thickness and lakebed hydraulic conductivity. Note that in the Lake package, the thickness and hydraulic conductivity are specified in the aquifer cells next to the lake rather than in the lake itself.

\section{Multiplier Layers and Zone Layers (Information; Nearest, Exact)}

Multiplier Layers and Zone Layers are used to define multiplier arrays and zone arrays in MODFLOW-2000.

\section{Head Observations[i] (Information; Nearest)}

The Head Observations[i] layers are used to define head observations. If the head observation spans more than one layer, the weights assigned to different model layers is determined in part by the transmissivity of the model layer.

\section{Weighted Head Observations[i] (Information; Nearest)}

The Weighted Head Observations[i] layers are used to define head observations where the weights assigned to different model layers is determined in part by the userspecified weights of the geologic units.

\section{GHB Observations[i], Drain Observations [i], and River Observations[i] (Information; Exact)}

GHB Observations[i], Drain Observations[i], and River Observations[i] are used to define General-Head Boundary, Drain, and River observations respectively.

\section{Prescribed_Head Flux Observations[i] (Information; Exact)}

Prescribed_Head Flux Observations[i] layers are used to define observations of flux at prescribed head cells.

\section{Advection Starting Points[i] (Information; Nearest)}

Advection Starting Points[i] layers are used to specify the starting points for advection observations.

\section{Advection Observation Points[i] (Information; Nearest)}

Advection Observation Points[i] layers are used to specify the end points for advection observations.

\section{Elevation Top Unit[i] and Elevation Bottom Unit[i] (Information; 624 Interpolation)}

Each geologic unit has a pair of Argus ONE layers entitled Elevation Top Unit[i] and Elevation Bottom Unit[i]. These two layers are used to specify the geometry of the geologic unit. Normally, the bottom of one unit should be the same as the top of the layer beneath it. An Argus ONE expression can be used to make sure this is true. 


\section{Added Inactive Area Unit[i] (Information; Exact)}

If more than one geologic units are present, some units might not be as extensive as others. The Added Inactive Area Unit[i] layers can be used to inactivate an area for one geologic unit while leaving it active in another geologic unit. To inactivate an area, draw a close contour around the area to be inactivated and assign the closed contour a value of 0 .

\section{Prescribed Head Unit[i] (Information; Exact)}

A prescribed head cell is a cell that will have the same head throughout the duration of a model. Any cell whose center is inside a closed contour or that intersects a point or open contour on the Prescribed Head Unit[i] layer will be prescribed head cell with the head defined by that contour.

\section{Initial Head Unit[i] (Information; 624 Interpolation)}

Initial Head Unit[i] layers are used to specify the head in every cell at the start of the model (except at prescribed head cells).

\section{Hydraulic Cond Unit[] (Information; 624 Interpolation)}

Hydraulic Cond Unit[i] layers are used to specify the hydraulic conductivity in the $\mathrm{X}$ and $\mathrm{Z}$ directions. (The hydraulic conductivity in the $\mathrm{Y}$ direction is usually set by the Anisotropy which is set on the Geology tab of the Project Info dialog box.)

\section{Specific Yield Unit[i] and Specific Storage Unit[i] (Information; 624 Interpolation)}

Specific Yield Unit[i] and Specific Storage Unit[i] set the storage parameters for the geologic unit under unconfined and confined conditions respectively. The storage parameters are only used in transient models.

\section{Wetting Threshold Unit[i] (Information; Exact)}

Wetting Threshold Unit[i] layers are used to determine the conditions under which dry can become wet when the wetting option is active. If the wetting option is not active, this layer is ignored. The wetting option is activated on the Wetting tab of the Project Info dialog box as described previously. The wetting threshold determines how high above the base of the dry cell the head in a neighboring cell must be before a dry cell can convert to wet. The Wetting Flag determines which neighboring cells can cause a dry cell to become wet. If Wetting Flag is 1 , all a cells neighbors (except the cell above) can cause it to become wet. If Wetting Flag is -1 , only the cell beneath a dry cell can cause it to become wet. This is appropriate if large head differences between adjacent cells are expected. If Wetting Flag is 0 , the cell can not be wetted.

\section{Wells Unit[i], Line Wells Unit[i], and Area Wells Unit[i] (Information; Nearest, Nearest, Exact) \\ Wells Unit[i], Line Wells Unit[i], and Area Wells Unit[i] are used to specify} wells in the Well package using point, open, and close contours respectively. Of course, real wells would not normally be represented by open and close contours but there are 
often occasions where modelers wish to specify a known flux along a line or over an area. The Line Wells Unit[i], and Area Wells Unit[i] layers facilitate this. The Top Elevation and Bottom Elevation Argus ONE parameters are important if the vertical discretization of a geologic unit is greater than one. In such cases, the top and bottom of the well screen is compared with the top and bottom of each layer in the geologic unit to determine what proportion of the pumpage from the well should be applied to each layer. In the case of Line Wells Unit[i], and Area Wells Unit[i], either a pumping rate per unit length or per unit area or a total pumping rate for the contour can be specified.

\section{Point River Unit[i], Line River Unit[], and Area River Unit[]] (Information; Nearest, Nearest, Exact)}

Point River Unit[i], Line River Unit[i], and Area River Unit[i] are used to specify rivers in the River package using point, open and close contours respectively.

\section{Point Drain Unit[i], Line Drain Unit[i], and Area Drain Unit[i] (Information; Nearest, Nearest, Exact)}

Point Drain Unit[i], Line Drain Unit[i], and Area Drain Unit[i] are used to specify drains in the Drain package using point, open, and close contours respectively.

\section{Point, Line, and Area Gen Head Bound Unit[i] (Information; Nearest, Nearest, Exact)}

Point Gen Head Bound Unit[i], Line Gen Head Bound Unit[i], and Area Gen Head Bound Unit[i] are used to specify general-head boundaries in the General-Head Boundary package using point, open, and close contours respectively.

\section{Stream Unit[i] (Information; Nearest)}

Stream Unit[i] layers are used to designate the locations of streams for the stream package. The stream direction is important on these layers. Stream direction is determined by the order in which the nodes in the open contour representing the stream are drawn. The first node in the contour is the upstream end. The last node in the contour is at the downstream end. For contours with 3 or more nodes, the upstream end can be distinguished by the position of the label on the contour. The label is between the first and second nodes and is thus at the upstream end of the contour. If a contour only has two nodes, the user can copy the contour to the clipboard and paste it in a text editor. The user can examine at the coordinates of each node in the text editor to determine which end is which. The upstream end will be the first node.

Streams have several features that can be determined by linear interpolation along the length of the stream. These include the stage, bottom elevation, top elevation, and width. In all such cases, there are two Argus ONE parameters for that feature named "Upstream < feature $>$ " and "Downstream < feature $>$ " where "<feature $>$ " is the name of the feature that will be determined by linear interpolation. Expressions used to assign values to the "Downstream" Argus ONE parameters will be evaluated at the first (i.e. upstream) node of the contour. See the section entitled "Evaluating Expressions at Specific Locations" for a way around this limitation. 


\section{Horizontal Flow Barrier Unit[i] (Information; Nearest)}

The Horizontal Flow Barrier Unit[i] layers are used to define horizontal flow barriers with open or close contours. Only open or closed contours should be used on Horizontal Flow Barrier Unit[i]. Argus ONE does not have an entirely satisfactory way of visualizing the locations of barriers so one was built into the MODFLOW GUI. For more information on visualizing Horizontal Flow Barriers see the section entitled "Visualizing Input Data".

\section{Point FHB Unit[i], Line FHB Unit[i], and Area FHB Unit[i] (Information; Nearest, Nearest, Exact)}

Point FHB Unit[i], Line FHB Unit[i], and Area FHB Unit[i] are used to specify the location of flow-and-head boundaries in the Flow and Head Boundary package using point, open, and close contours respectively. On the Line FHB Unit[i], the direction of the open contours is important. The contour direction can be determined in the same way it is for contours on the Stream Unit[i] layers.

\section{MODPATH Zone Unit[i] (Information; Exact)}

MODPATH Zone Unit[i] layers represent the zone codes used by MODPATHPLOT to determine the color of pathlines and particle points. MODPATH requires that the zone code lie between 1 and 999 inclusive. In the MODPATH|Options tab of the Project Info dialog box, a zone in which particles will stop if they enter it can be designated.

\section{MODPATH Particles Unit[i] (Information; Exact)}

The MODPATH Particles Unit[i] layers are used to specify the locations and release times of particles for MODPATH.

\section{Particle Regeneration Unit[i] (Information; Exact)}

Particle Regeneration Unit[i] layers are used to flag strong fluid sources with a 1 to indicate to MOC3D that new particles will need to be created to replace those advected out of the cell.

\section{Init Concentration Unit[i] (Information; Exact)}

Init Concentration Unit[i] layers are used to specify the initial concentration of solute in MOC3D.

\section{Porosity Unit[i] (Information; Exact)}

Porosity Unit[i] layers are used to specify the porosity of a geologic unit for MOC3D and MODPATH.

\section{ZONEBDGT Unit[i] (Information; Exact)}

ZONEBDGT Unit[i] layers are used to designate zones for use in ZONEBUDGET. 


\section{Other Layers}

The layers listed above are not an exhaustive list of layers that may be created by the MODFLOW GUI. All the layers created by the MODFLOW GUI are described in detail in the online help for the MODFLOW GUI.

\section{Evaluating Expressions at Specific Locations}

In some cases, users may wish to evaluate an expression at a particular location that is not the same as the location where it would normally be evaluated. For example, with streams, there are "Upstream" and "Downstream" parameters that are meant to apply to the upstream and downstream end of the stream. However, expressions are always evaluated at the first node of a contour, which would be the upstream end of a stream. To overcome this difficulty, a new utility PIE, EvalAtXY.dll, was developed that allows the user to evaluate an expression at a specific location. The PIE has four functions: EvalRealAtXY, EvallntegerAtXY, EvalBooleanAtXY, and EvalStringAtXY. These return real numbers, integers, Booleans (true/false values), and strings respectively. Each function has three required and one optional arguments. The three required arguments are

- $\mathrm{X}=$ the $\mathrm{X}$ coordinate at which the expression is to be evaluated (real number)

- $Y=$ the $Y$ coordinate at which the expression is to be evaluated (real number)

- Expression = the expression to be evaluated expressed as a quoted string (string) The optional argument is

- Layer Name = the name of the layer on which the expression is be evaluated expressed as a quoted string (string)

If "Layer Name" is not provided, the expression will be evaluated on the layer that calls the expression. It is important to include both the "Expression" and "Layer Name" arguments inside quotation marks so that they will be passed to the expression properly. If this is not done, the functions can not work properly.

An example of how to use one of the EvalAtXY functions to set the top elevation of a stream would be the following. First set up a layer named Elevation that will represent the elevation of a stream bed. Next, for Stream Unit[i].Upstream top elevation[i], set the expression to Elevation. This links the Upstream top elevation[i] parameter to the Elevation layer. Argus ONE will evaluate the expression at the first node in the contour which is the upstream end of the contour. For Stream Unit[i].Downstream top elevation[i], set the expression to EvalRealAtXY(NthVertexX(NumVertices0), NthVertexY(NumVertices0), "Elevation"). NumVertices ( returns the number of verticies in the contour. Nth VertexX and NthVertexY return the $X$ and $Y$ coordinates of the vertex number passed to them as an argument. In this case the vertex number passed to them is the number of verticies so they will return the $X$ and $Y$ coordinates of the last vertex. These are then passed to EvalRealAtXY along with the expression to be evaluated at those coordinates which is Elevation. Note however the quotation marks around Elevation in the full expression. If those quotation marks were not present, the expression would be evaluated before being passed to EvalRealAtXY and thus would be evaluated at the usual Argus ONE location rather than at the $X$ and $Y$ coordinates passed to EvalRealAtXY. 


\section{Importing Data}

There are several ways to import data into Argus ONE. Generally, data are imported into information or data layers. The most basic way of importing information into these layers is to prepare a text file in the format described in the Argus ONE documentation (Argus Interware, Inc., 1997; p. 104-107 and p 9 s2.5 to $15 \mathrm{~s} \mathrm{2.5)} \mathrm{and} \mathrm{then}$ select the File|Import command in Argus ONE. Argus ONE also has a built in capacity to import DXF files. Argus ONE also comes with a free Plug-In Extension that allows users to import Shape files. (Argus Interware sells another PIE that allows users to export to Shape files from Argus ONE.) Argus ONE also has a "spreadsheet" PIE. This PIE is intended for importing a list of scattered points, specified in a spreadsheet-like text file, into Data or Information layers.

The MODFLOW GUI has a built in method for importing Well data. To use it select PIEs|Import Wells. The dialog box that is displayed will have several options including one for copying data from the clipboard. For details on how to use this method, click on the Help button on the dialog box.

Another option for importing data is the GriddedImport PIE developed in conjunction with version 4 of the MODFLOW GUI. To use the GriddedImport PIE, the user must first create a grid in your model. The GriddedImport PIE will create a data layer with a data point located at the center of each cell in the grid. The PIE is activated by selecting PIEs|Import gridded data from the main Argus ONE window. After selecting the grid layer, a dialog box will appear where the user can paste the data from the clipboard. The help file for the GriddedImport PIE can be accessed by clicking the Help button on the dialog box. Although, this PIE was developed with the MODFLOW GUI in mind, it can be used with any Argus ONE project that has a finite-difference grid.

The GriddedImport PIE can be useful in importing data from existing MODFLOW models into Argus ONE. To do so, first recreate the grid from the original model in MODFLOW. If needed, grid lines can be added manually, removed or their positions may be adjusted to make the grid match the grid in the existing model. Next select "PIEs|Import Gridded Data". After selecting a grid layer, a dialog box will be displayed. Determine the data format of your data and whether or not the data has multiple lines of data per grid row. Set the options accordingly. If you wish to use the clipboard to transfer the data, copy the data to the clipboard and paste it into the table by clicking on the "Paste from clipboard" button. If you wish to read the data from one or more files, click the "Read from files" button. Assign a name for the data layer. If the user wishes to have more than one Argus ONE parameter for each data point, set the "number of data sets" to the number of sets of data to be inserted. The PIE can ignore values if desired. Finally click on the OK button to create the data layer. The user can link to this layer from the appropriate information layers.

To import a complete existing MODFLOW-88 or MODFLOW-96 model into Argus ONE do the following.

- Create a new model.

- Select PIEs|Edit Project Info... and go to the Advanced Options tab.

- Click the Import MODFLOW model button.

- In the dialog box that appears, provide the required information and click the Next button. 
- When all the required information has been provided, the Next button will change to a Finish button. Click the Finish button to import the data into Argus ONE.

Some information, such as the top and bottom elevations of layers, may not be imported because it isn't present in the MODFLOW model. You must still define such information before you can run your model.

At present, information from the following packages is imported into Argus ONE.

- Basic (BAS)

- Block-Centered Flow version 3 (BCF)

- Direct Solution (DE4)

- Drain (DRN)

- Evapotranspiration (EVT)

- General-Head Boundary (GHB)

- Preconditioned Conjugate Gradient (Version 2) (PCG)

- Recharge ( $\mathrm{RCH})$

- River (RIV)

- Strongly Implicit Procedure (SIP)

- Slice-Successive Overrelaxation (SOR)

- Well (WEL)

\section{Editing Data Layers}

Argus ONE, does not provide a mechanism for editing the values of data points in a data layer. To overcome this limitation, a new PIE was written that allows users to edit data values. To use the new PIE make a data layer the active layer and select "File|Import < data layer name $>$ Edit Data Layer". A resizable dialog box will appear showing the all the data points in both a graphical format and in a table. In the graphical format, the user edits a data point by clicking on a point. This will display a resizable dialog box in which the user can edit the parameter values and location for the selected data point. In the table, the data points are listed with their $\mathrm{X}$ and $\mathrm{Y}$ coordinates. The user can edit both the parameter values and the location of the data points in the table. The user can also add new data points or delete existing ones in the graphical view.

The same PIE that is used to edit data layers can also be used to convert contours into data points on a data layer. To do this select "File|Import < data layer name $>$ |Contours to Data Layer". Then select the information layer from the list of information layers first dialog box and enter the name of a new or existing data layer in the second dialog box.

\section{Visualizing Input Data}

Visualizing the gridded data generated by the MODFLOW GUI can help in understanding a model. For example, visualizing the geospatial information linked to the finite-difference grid may indicate if discretization is too coarse to capture the spatially varying nature of certain hydrologic properties. Visualize the geospatial information linked to the finite-difference grid in the layer MODFLOW FD Grid. To visualize gridded data:

- Make MODFLOW FD Grid the active layer. 
- Use the cursor to click and hold the triangle to the right of the color legend in the tool palette. A menu with the list of the Argus-ONE parameters linked to the finitedifference grid will appear.

- Select one of the parameters in the menu. The grid will be colored according to the value of the selected parameter.

- The colors can be controlled using the "View|Colors" command.

Double click on a cell to see the values of all the parameters on the layer for that cell. Override the values for an individual block by entering a new value in the dialog box.

Add new parameters to the MODFLOW FD Grid if the existing parameters don't show the desired information. The Argus ONE documentation describes how to add new parameters to a layer (Argus Interware, Inc., 1997, Part 2, Chapter 3, p 126132).

In the case of Horizontal Flow Barriers, Argus ONE doesn't have a good method for displaying where the barriers will be placed so one was built into the MODFLOW GUI. Select PIEs|Display Horizontal-Flow Barriers to show a dialog box that can show the locations of Horizontal-Flow Barriers in a model. Next type the unit number of the unit in the edit box and click the "Display" button. If there are barriers on the selected unit, they will be displayed. If not, a warning message will appear.

The grid is shown on the dialog box without any rotation. If the model has a coordinate system where $\mathrm{X}$ increases from right to left or $\mathrm{Y}$ increases from top to bottom, this is not detected so the grid will be shown reversed from what it really is. There are check boxes in the dialog box that can be used to indicate the correct direction.

At present there is no zooming capability on this dialog box but it can be resized the dialog box to make the grid larger.

Click on the Close button to close this dialog box.

\section{Running MODFLOW, MOC3D, MODPATH, or ZONEBUDGET}

To run MODFLOW, MOC3D, MODPATH, or ZONEBDGT first make the MODFLOW FD Grid layer the active layer. Then select "Run MODFLOW/MOC3D", "Run MODPATH", or "Run ZONEBDGT" from the PIEs menu. The Run model dialog box will appear. Use the radio buttons to select which model to run and whether or not to run the model or just create the input files for the model. For MOC3D models, users can choose to either run MODFLOW (without solute transport) or MOC3D (with solute transport) by checking or unchecking the "Include MOC3D to simulate solute transport" check-box. At the time this was written, MOC3D only worked with MODFLOW-96 so if MOC3D is selected, the model will be changed to a MODFLOW-96 model and a warning will be given. (A future version of MOC3D may work with MODFLOW-2000. If so, the MODFLOW GUI may be changed to remove this restriction.) The user can also click the Edit Project Info button to edit the MODFLOW non-spatial data. If the input files for a model have already been created and the data for one or more packages have not changed since the last time the input file was created, there is no need to create a new copy of that input file. Instead, the user can save time during the process of exporting the MODFLOW input files by not exporting new copies of the input files for the packages that haven't changed. All those 
packages whose check-boxes are both checked and enabled will be exported to the MODFLOW input files. If a check box is unchecked, the package will still be used in the model but no new input file will be created.

In some special cases, the user may elect to develop their own export template for one or more MODFLOW Packages. In such cases, there is no need for the usual export template to create the input files for those packages so the user may elect not to create them with the usual export template.

The full paths to the executables should be displayed in edit-boxes on the "Model Paths" tab of the Run model dialog box. (This dialog box is displayed if the user selects PIEs|Run MODFLOW/MOC3D.) If the executable for the chosen model is not at the location specified in the edit-box, the background of the edit-box and the status bar will change to red and a warning message will be displayed in the status bar to indicate that the path is incorrect. Although it is possible to export the input files using an incorrect path, Argus $\mathrm{ONE}^{\mathrm{TM}}$ will not be able to start the model if the path is incorrect. If any of the non-spatial data for the model need to be edited, click the Edit Project Info button to show the Project Info dialog box. Click on the OK button in the Run model dialog box to begin exporting the input files for the selected program. Click on the Cancel button to close the Run model dialog box without exporting input files for any program.

If the OK button is clicked, another dialog box will appear. Use it to select the directory for storing the input and output files for your model. The file name in this dialog box can be ignored because the root name of the files to be created and the extensions for these files are specified in the Output Files tab of the Project info dialog box and on the Run model dialog box.

The ASCII files created from Argus ONE for executing MODFLOW and the other programs can be viewed by using any text editor. It may be desirable to view and edit these files created for the modeling program if the user is familiar with the file structure and data input for the modeling program and only minor changes are needed for additional simulations. However, it is usually easier to make these changes in the MODFLOW GUI and export the file again.

Because MODPATH and ZONEBDGT use the output from MODFLOW (or MOC3D) as part of their input, the user must ensure that the required output files are in the directory in which MODPATH or ZONEBDGT will be run. Normally, this is most easily accomplished by running MODPATH or ZONEBDGT in the same directory in which the model was run.

\section{Visualizing Results}

\section{Visualizing Results from MODFLOW and MOC3D}

The quick visualization of model results is important in facilitating the modeling process so that changes in project information and geospatial information can be made, and additional simulation can be conducted with minimum delay. For this purpose, a postprocessing PIE has been developed for MODFLOW and MOC3D simulation results. The postprocessing PIE uses the following files from MODFLOW, listed in table 3. 
Table 3. File Types Used for Postprocessing

\begin{tabular}{lc}
\hline \multicolumn{1}{c}{ File type } & Extension \\
\hline formatted text files for hydraulic head & fhd \\
formatted text files for drawdown & fdn \\
binary files for hydraulic head & bhd \\
binary files for drawdown & bdn \\
formatted text files for concentration & cna \\
formatted text files for velocities & vla \\
formatted text files for 1\% scaled sensitivities & sea \\
binary files for subsidence & iss \\
binary files for critical head & ish \\
binary files for compaction & isc \\
\hline
\end{tabular}

The binary files must be created by a version of MODFLOW compiled with the Lahey LF90 compiler or one compatible with it. If some other compiler is used, ReaArr.dll must be recompiled with the same compiler as was used to compile MODFLOW. The program "Translator" installed in the same directory as the MODFLOW GUI can be used to test recompiled versions of ReArr.dll. "Translator" reads a binary head or drawdown file and writes a text file with the same information.

The postprocessing PIE for MODFLOW is launched from within the Argus ONE application. The postprocessing PIE for MODFLOW uses information from the layer MODFLOW FD Grid. Therefore, it is necessary to have a project file open with the finite-difference grid that was used to generate the output files. If changes have been made in the geospatial information without changing the finite-difference grid, then multiple files can be visualized using the same project file even though the current geospatial information has been altered. However, if changes are made in the finitedifference discretization in the layer MODFLOW FD Grid, and the visualization of simulations made with previous finite-difference grids is desired, the user should save the project file before making changes in the finite-difference discretization using the Save As... command in the File pull-down menu.

To visualize the results of a MODFLOW or MOC3D model, select "PIEs|MODFLOW/MOC3D Post Processing". A dialog box will appear to choose to read output from one of the file types listed in table 4. Choose the type of data to visualize and click on the "Select Data Set" button. Depending on the data type chosen, one or more of the file types listed in table 4 will be available for selection. Only files that were created with the finite-difference grid in the MODFLOW FD Grid layer of the current project file should be selected.

The data sets in the file will be read and their captions displayed in the MODFLOW Post-Processing dialog box. Choose the data set or sets to plot and choose the type of chart to create and the model layer in this dialog box. Click OK to create a data layer containing the data and a map layer containing the postprocessing charts. If the default name for either or both of these layers already exists, the "Layer Already Exists" dialog box will appear. Radio buttons on this dialog box allow the user to choose between overwriting the existing layer and creating a layer with a new name. If the latter option is selected, either accept a default name or an arbitrary new name may be used. 
If a velocity file was read, the radio buttons for chart type will be disabled and a vector plot will be created. See the Argus ONE documentation for more information about vector plots (Argus Interware, Inc., 1997, p. 31 s 2.5). To create a vector plot choose pairs of $X$ and $Y$ velocities. The $Z$ velocities will also be read and displayed on the list of available data sets but the PIE does not have a method for creating velocity plots along vertical profiles.

Clicking on a postprocessing object in the layer MODFLOW Post Processing Charts will bring up a dialog box that can be used to alter the appearance of the postprocessing object. Additional information on creating and modifying the appearance of postprocessing objects is given in the Argus ONE User's Guide (Argus Interware, Inc., 1997 , p. 23 s 2.5 - 43 s 2.5 ).

In the following, a brief description of the postprocessing methods is given.

\section{Contour Map}

Selecting the contour map option produces a contour map of hydraulic head, drawdown, concentration, or 1 percent scaled sensitivity in the selected layer for the selected time steps. If only one time step is selected, the contour map will overlay the finite-difference grid. If more than one time step is selected, then the selected contour maps will be scaled and placed in the layer MODFLOW Post Processing Charts.

\section{Color Map}

Selecting the color map option produces a colorized interpolation of the hydraulic head, drawdown, concentration, or 1 percent scaled sensitivities in the selected layer for the selected time steps. If only one time step is selected, the color map will overlay the finite-difference grid. If more than one time step is selected, then the selected contour maps will be scaled and placed in the layer MODFLOW Post Processing Charts.

\section{Three-Dimensional Surface Map}

Selecting the three-dimensional surface map option produces a colorized threedimensional perspective map of hydraulic head, drawdown, concentration, or 1 percent scaled sensitivities in the selected layer for the selected time steps.

\section{Cross Section}

Selecting the cross-section option produces a plot of the hydraulic head, drawdown, concentration, or 1 percent scaled sensitivities as a function of distance along a line through the modeled domain. The hydraulic head or drawdown from more than one time step can be included on the cross-section by choosing more than one time step in the Data dialog for the MODFLOW postprocessor. It is also possible to draw a cross section of the hydrogeologic framework and choosing the appropriate parameters from the grid or data layer.

\section{Visualizing MODPATH results}

To plot the results from MODPATH, the user may either use MODPATH-PLOT (a separate program) or use Argus $\mathrm{ONE}^{\mathrm{TM}}$ to display the results. To use Argus $\mathrm{ONE}^{\mathrm{TM}}$ to display the results, select PIEs|Plot MODPATH Results. The Plot MODPATH Results dialog box will appear. Choose the type of data to import by selecting the data 
type in the group of radio buttons labeled Data type. Click on the Read Data button and select the file. The data will be displayed in the dialog box. For endpoint files, there will also be a statistical summary of the data. After clicking OK, the data will be plotted as contours in an Argus ONE ${ }^{\mathrm{TM}}$, information layer named MODPATH Pathlines or MODPATH Endpoints. Pathline contours will have four Argus-ONE parameters Starting Layer, Starting Time, Ending Layer, and Ending Time. Endpoints will have two additional Argus-ONE parameters: Starting Zone and Ending Zone.

The statistical summary of MODPATH endpoints includes information about travel distance and travel velocity. This distance refers only to the distance traveled in a straight, horizontal line from the starting to the ending point. Vertical travel and deviations from a straight line along the travel path are ignored. The velocities are calculated from the horizontal, straight-line distances and thus have the same limitations as the distances.

\section{Analyzing Results}

In many cases, it is useful to display the results of a model graphically. For spatial information, the methods described in the previous section entitled "Visualizing Results" are useful, but in many cases, the data is of a different nature that is not suitable for display in Argus ONE. GW_Chart was developed to meet this need.

GW_Chart is a program for creating specialized graphs used in ground-water studies. It incorporates the functionality of two previous programs, Budgeteer and Hydrograph Extractor (Winston, 1999), and adds additional new features. Five major types of graphs can be created with GW_Chart: Calibration Plots, Water Budget Plots, Hydrographs, Lake Plots, and Piper Diagrams

Start GW_Chart in the same way as any typical Windows program would be started. This opens the main form of the program. From there, choose the type of chart to be created and the source of the data. Then open the appropriate output file. The data are extracted and plotted. The graphs can be formatted in a variety of ways and saved to graphics files or printed. The data for the graph can be saved in a tab-delimited format. This format is readily imported into spreadsheets and other commonly available software.

The help file for GW_Chart can be opened by clicking on the Help|Help menu item in GW_Chart. The help file documents the various options in GW_Chart.

\section{Examples}

In conjunction with development of version 4 of the MODFLOW GUI, ten example models were developed to illustrate how to use the MODFLOW GUI. Step-bystep instructions on how to recreate the models as well of the models themselves are available for downloading along with the MODFLOW GUI. The instructions are in a Windows Help file named Mftut.hlp. Two of the examples are reworked from previous version of the MODFLOW GUI (Hornberger and Konikow, 1998; Winston, 1999). The other eight are adapted from examples presented in the documentation of the observation, sensitivity, and parameter-estimation processes (Hill and other, 2000), the Resevoir package (Fenske and others, 1996), the Transient Leakage package (Leake and others, 1994), the Interbed Storage package (Leake and Prudic, 1991), and the Lake package (Merritt and Konikow, in press). 
A separate web-based tutorial is also available along with the MODFLOW GUI. It was developed by Argus Interware based primarily on Andersen (1993). The webbased tutorial focuses both on the operation of Argus ONE and the proper use of MODFLOW.

The examples and tutorials are meant to introduce the features of MODFLOW, Argus ONE, and the MODFLOW GUI. Thus, they may prove most useful for users who are unfamiliar with one or more of the above programs.

\section{References}

Andersen, P.F., 1993, A Manual of Instructional Problems for the USGS MODFLOW Model: Robert S. Kerr Environmental Research Laboratory, Office of Research and Development, U.S. Environmental Protection Agency, P.O. Box 1198, Ada, Oklahoma, 74820 EPA/600/R-93/010, 280 p.

Argus Interware, Inc., 1997, User's Guide Argus ONE ${ }^{\mathrm{TM}}$, Argus Open Numerical Environments - A GIS Modeling System, Version 4.0, Jericho, NY, Argus Holdings, Limited, 506 p.

Fenske, J.P., Leake, S.A., and Prudic, D.E., 1996, Documentation of a computer program (RES1) to simulate leakage from reservoirs using the modular finite-difference ground-water flow model (MODFLOW): U.S. Geological Survey Open-File Report 96-364, $51 \mathrm{p}$.

Harbaugh, A.W., and McDonald, M.G., 1996a, User's documentation for MODFLOW96, an update to the U.S. Geological Survey modular finite-difference groundwater flow model: U.S. Geological Survey Open-File Report 96-485, 56 p.

Harbaugh, A.W., and McDonald, M.G., 1996b, Programmer's documentation for MODFLOW-96, an update to the U.S. Geological Survey modular finitedifference ground-water flow model: U.S. Geological Survey Open-File Report 96-486, $220 \mathrm{p}$.

Harbaugh, A.W., Banta, E.R., Hill, M.C., and McDonald, M.G., 2000, MODFLOW2000, The U.S. Geological Survey Modular Ground-Water Model--User's Guide to Modularization Concepts and the Ground-Water Flow Process: U.S. Geological Survey Open-File Report 00-92, 191 p.

Hill, M.C., 1998, Methods and guidelines for effective model calibration: U.S. Geological Survey, Water-Resources Investigations Report 98-4005, 90 p.

Hill, M.C., Banta, E.R., Harbaugh, A.W., and Anderman, E.R., 2000, MODFLOW-2000, The U.S. Geological Survey Modular Ground-Water Model -- User's Guide to the Observation, Sensitivity, and Parameter-Estimation Processes and Three PostProcessing Programs: U.S. Geological Survey Open-File Report 00-184, 220 p.

Hornberger, G.Z., and Konikow, L.F., 1998, Addition of MOC3D solute-transport capability to the U.S. Geological Survey MODFLOW-96 graphical-user interface using Argus Open Numerical Environments: U.S. Geological Survey Open-File Report 98-188, $30 \mathrm{p}$.

Leake, S.A., Leahy, P.P., and Navoy, A.S., 1994, Documentation of a computer program to simulate transient leakage from confining units using the modular finitedifference ground-water flow model: U.S. Geological Survey Open-File Report 94-59, $70 \mathrm{p}$. 
Leake, S.A. and Prudic, D.E., 1991, Documentation of a computer program to simulate aquifer-system compaction using the modular finite-difference ground-water flow model: U.S. Geological Survey Techniques of Water-Resources Investigations, Book 6, Chapter A2, 68 p.

McDonald, M.G., Harbaugh, A.W., Orr, B.R., and Ackerman, D.J., 1992, A method of converting no-flow cells to variable-head cells for the U.S. Geological Survey modular finite-difference ground-water flow model: U.S. Geological Survey Open-File Report 91-536, 99 p.

Merritt, M.L., and Konikow, L.F., in press, Documentation of a computer program to simulate lake-aquifer interaction using the MODFLOW ground-water flow model and the MOC3D solute-transport model: U.S. Geological Survey WaterResources Investigations Report 00-4167.

Shapiro, A.M., Margolin, J., Dolev, S., and Ben-Israel, Y., 1997, A graphical-user interface for the U.S. Geological Survey modular three-dimensional finitedifference ground-water flow model (MODFLOW-96) using Argus Numerical Environments: U.S. Geological Survey Open-File Report 97-121, 50 p.

Winston, R.B., 1999, Upgrade to MODFLOW-GUI: Addition of MODPATH, ZONEBDGT, and additional MODFLOW packages to the U.S. Geological Survey MODFLOW-96 Graphical-User Interface: U.S. Geological Survey OpenFile Report 99-184, 63 p. 